\title{
Being realistic about motivation
}

\author{
Charlie Kurth ${ }^{1}$ (D)
}

(C) Springer Nature B.V. 2018

\begin{abstract}
T.M. Scanlon's 'reasons fundamentalism' is thought to face difficulties answering the normative question - that is, explaining why it's irrational to not do what you judge yourself to have most reason to do. I argue that this difficulty results from Scanlon's failure to provide a theory of mind that can give substance to his account of normative judgment and its tie to motivation. A central aim of this paper is to address that deficiency. To do this, I draw on broadly cognitivist theories of emotion (those of, e.g., Martha Nussbaum and Robert Roberts). These theories are interesting because they view emotions as cognitive states from which motivation emerges. Thus, they provide a model Scanlon can use to develop a richer account of both the judgment-motivation connection and the irrationality of not doing what you judge yourself to have most reason to do. However, the success on this front is only partial-even this more developed proposal fails to give a satisfactory answer to the normative question.
\end{abstract}

Keywords Reasons fundamentalism - Scanlon - Normative question · Motivation · Emotion · Practical irrationality

A good metanormative account will answer what's known as the normative question: it will explain the robust connection that we find between normative judgment and motivation and do so in a way that allows us to understand the irrationality of failing to do what you judge yourself to have most reason to do. On this score, the quietist non-naturalist realism of T. M. Scanlon (1998), Derek Parfit

Charlie Kurth

charles.kurth@wmich.edu

1 Department of Philosophy, Western Michigan University, 1903 W. Michigan Ave, Mail Stop 5328, Kalamazoo, MI 49008, USA 
(2011), Ronald Dworkin (1996), and others has been deemed unsatisfactory. According to these quietists, the central normative concept of a reason resists analysis. So while they hold that reasons are facts about the non-natural normative domain, they insist that little else can-or need be-said about them. It's here that the normative question gets its grip. Given the quietists' insistence that there's little to be said about reasons, we don't get an informative account of the connection between normative judgment and action or the error in not doing what you take yourself to have (most) reason to do. For instance, Jamie Dreier objects that

all the [quietist] can do is say that it is true that there is this connection [between normative judgment and motivation]. It's just a fact. The problem isn't that what the [quietist] has to say is false, or that nobody else would want to say it; the problem is that it offers nothing in the way of explanation. (2014a: 178; also: Korsgaard 2008; Gibbard 1990)

In short, a satisfactory response to the normative question seems to require more than what these quietists are able to provide. ${ }^{1}$

On this score, Scanlon's (2014) most recent proposal—what he calls 'reasons fundamentalism'-is interesting because he thinks that concerns about the quietists' answers to the normative question rest on a misunderstanding of what needs to be explained in the first place. Once we clear that up, we will see that there's no problem for quietists like himself. But assessments of the success of Scanlon's answer to the normative question are decidedly mixed (e.g., Parfit 2011; Dreier $2014 \mathrm{a}, \mathrm{b})$ and this, I believe, is because neither Scanlon nor his critics have done enough to develop the resources that reasons fundamentalism has to answer the normative question. A central aim of this paper is to address this deficiency. In particular, I'll argue that the key to a satisfactory reasons fundamentalist answer to the normative question lies in their ability to provide an account - a theory of mind - that can explain the mental state that's distinctive of normative judgement: we need an account of a cognitive state that while belief-like in having correctness conditions, nonetheless also has a robust rational connection to action. To develop such an account on Scanlon's behalf, I turn to broadly cognitivist theories of emotion (e.g., Nussbaum 2001; Roberts 2013). Cognitivist accounts are interesting in this regard because they take emotions to be belief- or perception-like states that have an intimate tie to motivation. So they're well-placed to serve as a model that reasons fundamentalists like Scanlon can draw on to give substance to their account of normative judgment. However, having fleshed out the reasons fundamentalist proposal, I will then argue that even this more developed account fails to provide an adequate response to the normative question.

\footnotetext{
1 While both "robust" non-natural realists (e.g., Enoch 2011; Shafer-Landau 2003) and quietist maintain that normative concepts are (largely) unanalyzable, quietism is distinct in maintaining that (non-natural) normative facts are minimally metaphysically committing. As such, quietists take themselves to be better equipped to address Mackie-style queerness worries and other metaphysical complaints about non-natural properties (c.f., McPherson 2010; Wodak 2017). Whether robust realists also face a challenge in answering the normative question is an issue for another time.
} 


\section{Scanlon's proposal}

Scanlon's discussion in Being Realistic about Reasons can be seen as offering a three-part answer to the normative question. The first move is to sharpen our understanding of what needs to be explained. Here Scanlon's starting place is the common thought that, in comparison to accounts that take normative judgments to be (or in some way involve) desires, quietists face a real challenge making sense of how normative judgments can motivate. After all, quietism takes normative judgment to be a belief-like state. So when we add the common thought that belieflike states are motivationally inert, quietism appears badly under-equipped to explain the tie between judgment and motivation (e.g., Smith 1994; c.f., ShaferLandau 2003). But as Scanlon sees it, this demand to account for the motivational dimension of judgments about reasons can be understood in two ways: as a demand for an account of how normative judgments could be causally efficacious with regard to one's subsequent actions or as a demand to explain how normative judgments could rationalize or make sense of the actions they're associated with (53).

Scanlon rejects the first option for two reasons. First, he argues that desires themselves don't actually do causal work. More specifically, Scanlon speculates that the reason some think desires cause action is because (in contrast with beliefs) we experience them as impulses - things that are motivationally laden. But this picture, he argues, is mistaken: while the object of our experience (i.e., the felt impulse of desire) may be associated with motivation in some way, it is not what actually does the causal work - that's done by the underlying neural mechanisms. Thus, it's just confused to think that desires (or beliefs for that matter) cause action (54). ${ }^{2}$ Second, and more significantly, Scanlon maintains that what we're really interested in when we ask about motivation is not causal power, but rather a certain rational connection (9-10, 53-54). It's this idea, namely, that there's a rational connection between judging something to be a reason and subsequent action, that Scanlon sees as central to our 'common-sense understanding of normative judgment.' Thus, providing an account of this rational tie is the real issue raised by the normative question (61). Moreover, Scanlon maintains that once we see that what we want when we ask about the connection between judgment and motivation is a rationalizing explanation-one that 'makes sense' of why someone did what they judged themselves to have most reason to do-we see that beliefs can do this rationalizing just as well as desires can. For instance, with regard to answering a question like, 'why did Mary help the stranger?' the response, 'she believed he needed help,' seems just as good as, 'she wanted to help him.' In both cases, the appeal to the mental state—be it a belief or a desire—not only makes sense of Mary's action, but

\footnotetext{
${ }^{2}$ Though I won't press the point, it's worth noting that Scanlon's argument against a causal role for desires appears to rest on an uncharitable rendering of how desire theorists understand both desires and their relation to motivation. In particular, Scanlon's argument seems to rest on a slide from thinking of desires in functional terms (i.e., as conative states) to thinking of them phenomenologically (i.e., as a particular type of felt urge). So while Scanlon may be correct that a mere feeling doesn't cause action, this is not the claim desire theorists are making.
} 
also draws out why it was rational for her to act as she did (53). The upshot is a significant first step in the development of a quietist response to the normative question.

The second step in Scanlon's answer to the normative question involves developing a cognitivist model of rational agency that can bolster the above suggestion that normative judgments - understood as beliefs - can rationalize (that is, make sense of and explain) action. As we have seen, Scanlon takes our commonsense understanding of agency to posit a rational connection between judgments about reasons on the one hand and motivations or actions on the other. To flesh this out, he introduces the idea of a perfectly rational agent (PRA). PRAs have two distinctive features that help us understand how normative beliefs can rationalize action (54). First, PRAs have the ability to both think about reasons and come to conclusions about what reasons are good reasons. Second, their judgments about the (good) reasons they have 'make a difference' to the actions and attitudes they subsequently have. From this account of what a PRA is, we get the rationalization we were looking for:

When a rational agent does something that he or she judges himself or herself to have reason to do, this judgment makes sense of the action in normative terms and explains it, because the action is what one would expect of a rational argent who accepted that judgment. (55, emphasis added)

More specifically, given Scanlon's account of what a PRA is, it would make sense that someone who believes they have a reason to do act $a$ in circumstances $c$ would (other things equal) do $a$. This, in turn, delivers an explanation of irrationality:

If the agent does not act [on what she judges herself to have conclusive reason to do]-if she refuses to consider $p$ as a reason, or declines to do $a$ even though realizing she is in circumstances in which she judges $p$ to be a compelling reason to $a$, then the person is being irrational. ... In cases of irrationality [the] normal processes fail to work properly, and the agent is not 'motivated' [by the reasons she judges herself to have]. (55-56)

While the above constitutes the core of Scanlon's response to the normative question, he is sensitive to the concern that his cognitivist model of rational agency — in eschewing appeals to desires_-might seem to 'succeed' only at the cost of an unintelligible theory of mind (61-66). After all, his account not only takes normative judgments to be beliefs, but also takes those beliefs to have a rational connection to motivation. But that combination is odd. As Scanlon notes, it makes normative beliefs significantly different from non-normative beliefs. Unlike beliefs about, say, middle-sized objects or mathematics, normative beliefs have both 'mindto-world' and 'world-to-mind' directions of fit-a combination that many see as dubious (Smith 1994: 112-125; c.f., Tanenbaum 2006). Scanlon's response-the third step in his answer to the normative question-is to argue that this 'direction of fit' objection fails.

To understand Scanlon's argument, some background will be helpful. Talk of directions of fit is standardly used to clarify the difference between belief- and desire-like mental states. States with a mind-to-world direction of fit are states that 
function to provide mental content that informs by representing the way the world is. This means that mind-to-world states are states that have correctness conditions: the state is correct just in case the world is as the state presents it to be. It also means that one is rationally criticizable if one doesn't correct the state when one has (sufficient) evidence that it fails to match the world. By contrast, states with a world-to-mind direction of fit are states that function to depict how the world (in some sense) should be. Thus, world-to-mind states don't have correctness conditions; rather, they have rational connections to action. Thus, one can be rationally criticized if one doesn't act to bring the world in line with the state. ${ }^{3}$ The direction of fit objection is then the claim that no single mental state can have both directions of fit. Though the explanation for the impossibility of dual-direction of fit states varies, the crucial point for our purposes is that according to the objection, (1) mind-to-world states like beliefs are states that are correct just in case they accurately represent the world and that (2) this representative function is (in some way) incompatible with the state also having a rational connection to motivation.

With this sketch of the direction of fit objection in hand, we can see Scanlon's response as a move to reject the motivational claim of (2) by contesting the plausibility of the representational claim of (1). More specifically, as he sees it, the claim that no state can have both mind-to-world and world-to-mind directions of fit only makes sense when 'world' refers to the natural world (65). Fleshing this out, Scanlon's point is that since judgments about the natural world are judgments about what the world contains, the correctness conditions of these judgments should be understood extensionally: does the content of the judgment fit the way the (natural/physical) world is? But not all (belief-like) judgments are like this. Mathematical judgments, for instance, have mind-to-world direction of fit, and so correctness conditions, even though the facts they concern are not about the natural world. Rather, the correctness conditions for mathematical judgments are 'internal' to the domain: they are correct just in case (and because) they accord with the relevant standards of mathematical reasoning (17-19).

But once we see that a state can have a mind-to-world direction of fit without also having extensionally specified correctness conditions, we see that it's possible that the correctness conditions of normative judgments could be grounded in something other than what obtains (or not) in the natural world. Moreover, the example of mathematics provides a model for what an alternative account would look like. It suggests that the correctness conditions of normative judgments are determined by the standards of practical reasoning - standards that, as Scanlon maintains, presume normative judgments have both mind-to-world and world-to-mind directions of fit (65-66). So contra the objection, it is possible for a mental state to have dualdirection of fit.

Taken together, Scanlon contends that these three steps provide a cognitivist model of rationality that isn't just 'intelligible' but-more importantly-accords with our 'common-sense understanding of normative judgment' (61). As such, he

\footnotetext{
${ }^{3}$ Whether one should be criticized in such a case turns on, inter alia, whether it would be (morally, prudentially) wrong to bring the world in line with one's state (desire).
} 
takes the resulting account of motivation to provide a viable, quietist answer to the normative question.

\section{Initial cause for concern: What is the reasons fundamentalism theory of mind?}

Scanlon's concerns about the viability of the standard direction of fit account of the belief/desire distinction may be well placed (e.g., Coleman 2008; Zangwill 1998). But rejecting it brings explanatory burdens. After all, the direction of fit model (DFM) provides us with an intuitive and explanatorily powerful way of understanding what's distinctive about beliefs and desires. So if Scanlon is going to reject the DFM, he owes us an alternative account of how this distinction should be understood. This demand for a plausible alternative is all the more pronounced given that Scanlon's rejection of the DFM is doubly qualified. For starters, while he denies that the DFM is applicable as an account of the correctness conditions of judgments about non-natural domains, he accepts it as an account of the correctness conditions for judgments about the natural world (65-66). Further complicating matters is Scanlon's second qualification: dual direction of fit states are not possible unless the state in question is one that concerns the normative domain (64).

Taken together, these qualifications make it difficult to understand what a reasons fundamentalist replacement for the DFM might look like. ${ }^{4}$ They also draw out that the plausibility of Scanlon's answer to the normative question turns on his ability to provide a viable reasons fundamentalist theory of mind. The discussion so far helps us understand what success on this front would involve. In particular, we need an account of (1) a genuinely cognitive or belief-like mental state that (2) has a rational tie to motivation. Moreover, the state in question must also be one that (3) it is reasonable to think beings like us possess and that (4) explains why the distinctive judgments of other non-natural domains (e.g., mathematics) do not have a similar rational tie to motivation. Finally, the account will (5) help us understand the error/ irrationality of failing to act on the reasons one takes oneself to have. In what follows, I explore what Scanlon might say in response to this five-fold explanatory demand $(\$ 3)$. I will then turn to question whether the resulting proposal can do the work he needs it to do $(\S 4)$.

\section{A reasons fundamentalist theory of mind}

\subsection{Building blocks of a reasons fundamentalist theory of mind}

To get a handle on what a reasons fundamentalist theory of mind might look like, we can start by returning to Scanlon's account of perfectly rational agents. PRAs,

\footnotetext{
4 Speculating, I believe Scanlon's doubly-qualified rejection of the DFM and the thinness of his alternative proposal is the source of recent dissatisfaction with his response to the normative question (e.g., Dreier 2014a, b).
} 
recall, have two distinctive features. First, they not only think about reasons but have the ability to reach conclusions about which of their reasons are good reasons. Second, PRAs are also such that their judgments about the (good) reasons they have make a difference their action: they tend to act in accordance with the judgments they make and do so because those judgments are in line with the (good) reasons they take themselves to have. I believe that a better understanding of what must be the case in order for a PRA to reach conclusions about whether she has good reasons to $a$ will help us understand why such an individual tends to be motivated by the normative judgments she makes. This, in turn, will provide us with resources we can use to develop a reasons fundamentalist alternative to the DFM.

Let's start with Scanlon's claim that a PRA will not only be able to cite the reasons she acted on if asked, but will also be able to defend her decision if challenged (54-55). On Scanlon's view, this is possible because coming to the conclusion that $p$ is a good reason to do act $a$ in circumstances $c$ does not involve just thinking about the merits of $a$. Rather, it is a holistic process in the sense that a PRA's conclusion that $p$ is a good reason to do act $a$ in $c$ does not involve just thinking about $a$. Rather, it's the upshot of thinking about, for instance, $p$ in relation to other potential considerations $\left(p^{*}, p^{* *}, \ldots\right)$ that might count for/against $a$. It also involves considering alternative courses of action $\left(a^{*}, a^{* *}, \ldots\right)$ in light of specific features of the situation at hand (i.e., the details of $c$ ). Once we see that Scanlon's account is holistic in this sense, we can see why he thinks a PRA will be able to defend her reason for acting as she did if she is challenged. After all, given the thought and reflection that is involved in coming to the conclusion that $p$ is a good reason to $a$ in $c$, a PRA will be well-placed to justify her judgment.

These observations also reveal that, for Scanlon, rational agency isn't (merely) a matter of having certain beliefs or understanding individual reasons. Rather, rational agency involves having certain packages of beliefs about one's situation and the range of actions one could take. It also involves appreciating the relations that these beliefs have to one another as well as to one's other mental states and actions (c.f., Tanenbaum 2006: 258). This rich understanding explains both how PRAs come to conclusions about the reasons they have and how the associated motivation to act develops. In short, on Scanlon's account, motivation is something that emerges from a rich understanding of one's reasons and one's situation.

This is progress. Appreciating the holism of Scanlon's account of the capacities of PRAs provides us with the makings of an account of normative judgment as a belief-like state that has a rational tie to motivation [i.e., it's the start of an answer to demands (1) and (2) from §2]. But more is needed. In particular, we need a better appreciation of what it might mean for motivation to 'emerge' from a rich understanding of one's reasons if it's to be more than just the positing of some magical elixir. We also need to understand how this framework helps us develop answers to demands (3)-(5).

On this front, I think we (and Scanlon) can get important insights from recent work on emotions. Emotions, after all, are states that, like Scanlon's account of normative judgment, seem to have both the correctness conditions of a belief-like state and the rational connections to action characteristic of a conative state (Deonna 
and Teroni 2012: 28-33). In fact, looking to the broadly cognitivist theories of emotion developed by Martha Nussbaum and, especially, Robert Roberts suggests that these structural parallels_-and so explanatory benefits-run even deeper.

\subsection{From emotional construals to normative motivation}

In presenting his account of emotions as a distinctive, conceptually-shaped form of perception, Roberts (2013: Chap 2) develops an analogy with what we do when we see the duck-rabbit figure as a duck rather than an abstract etching or see the string, 'fish fish fish fish fish,' not as the same word repeated five times, but rather as a meaningful sentence (on one of several possible parsings: fish that fish for fish catch fish). The cognitive process underlying these phenomena is something Roberts calls a 'construal'-roughly, a mode of access whereby a richer perception emerges from seeing a simpler structure in a particular way. Applying this to emotions, Roberts' idea is that emotional experience is undergirded by a similar kind of perception: to fear the snarling dog is to see-construe-the dog as a threat to one's well-being.

What makes construals like these interesting for our purposes is that they are cases where engaging a basic set of cognitive processes leads to the emergence of something richer: the representation of a duck emerges from what was initially seen just as an etching of an abstract form; a meaningful English sentence emerges from what was initially seen merely as the repetition of a single word; a concern for one's well-being emerges from what was initially just seen as a snarling dog. Thus, in Roberts' account of construals, we have something that could help us not only flesh out the Scanlonian suggestion that motivation is something that emerges from an understanding of one's reasons but also addresses the other explanatory demands from $\$ 2$. To draw this out, we need to take a closer look at the construals that we find in the duck-rabbit, fish, and fear examples.

The first thing to notice is that in Roberts' account of construals, we have something that engages familiar cognitive (i.e., belief-like) processes. From an understanding (perhaps implicit) of the fact that 'fish' can function syntactically both as a verb and as a noun as well as an understanding of the rules of English grammar, one comes to see-construe, understand-the repetitive string as a meaningful sentence. Moreover, notice as well that the phenomenon of (linguistic) construal is shaped and constrained not just by what our cognitive mechanisms can do, but also by the concepts and rules it engages (43-45). For example, the 'fish' string can be seen as a meaningful sentence because 'fish' can function as both a noun and verb in English, and because English grammar allows for rich forms of embedding.

Second, in the case of fear as the construal of a threat to one's well-being, we have a mode of (cognitive) access that's tied to motivation. More specifically, on Roberts' account, when one sees the dog as a threat-when one fears the dog-a concern for one's well-being emerges: one is motivated to (e.g.) avoid the dog or otherwise protect oneself (46-47). Making a similar point, Nussbaum maintains that the 'kinetic properties' of emotions - the way they move us-are things that emerge 
from the distinctive, and distinctly cognitive, content of one's emotions (2001: 44-46). ${ }^{5}$

Finally, Roberts' account of how we come to construe (say) the 'fish' string as meaningful allows for two forms of error. First, there's what we can call failures of understanding - the failures that result from not properly or fully understanding the relevant concepts, rules, and relations between them. For instance, one might not understand that 'fish' can function as both the subject and the object of a verb or that English grammar permits embedding of sub-sentential clauses. Given failures like these, one might be able to construe the short string 'fish fish' as meaningful. But one would be mistaken in thinking that longer, more complex strings like 'fish fish fish' and 'fish fish fish fish fish' were meaningless (Roberts 2013: 43-44). Second, there's what I'll call processing failures: the errors that come from a failure of the normal function of one's cognitive processes. Though one understands that the etching can be seen as depicting either a duck or a rabbit, and though one understands that (say) the long pair of protrusions at the top of the etching are supposed to be the ears of the rabbit, one still just cannot see the rabbit $(45,83-84)$. In such a situation, the cognitive mechanisms that underlie visual construal have broken down: one sees the parts and understands the relations between them, but the larger whole does not emerge.

With this elaboration of emotions as construals in hand, we're positioned to see how Scanlon might use it to meet the requirements for a viable alternative to the DFM. To do this, recall the five-fold demand from above. A plausible reasons fundamentalist theory of mind will provide an account of (1) a genuinely belief-like mental state that (2) nonetheless has a rational tie to motivation. Moreover, the state in question will be one that (3) it is reasonable to think beings like us possess and that (4) explains why the distinctive judgments of other non-natural domains like mathematics do not have a similar rational tie to motivation. Finally, the account will (5) capture our understanding of the distinctive error/irrationality of failing to act on the reasons one takes oneself to have.

In response, Scanlon can now note that, as we've seen, construals exclusively engage cognitive (i.e., belief-like) mental states. So in understanding normative judgment as akin to emotional construal, he captures condition (1). Moreover, the analogy with emotional construal also provides a model for understanding how motivation could emerge from a suitably rich understanding of one's situationallowing Scanlon to also secure condition (2). To see this, first recall the fear case. Given an understanding of (e.g.) the harm that a dog attack can do and an awareness that the Doberman before you has escaped his leash, you come to see the dog as a threat: you feel fear. A concern for your well-being-a concern to escape or avoid the approaching dog-thus emerges. In short, from the cognitive process of construing, one comes to see one's situation in a motivationally-laden way.

Mimicking this, Scanlon could argue that motivation emerges from a rich understanding — a construal—of how $p$ counts in favor of doing $a$ in $c$. To flesh this

\footnotetext{
5 As we will see $(\S 4)$, there are important differences in how Roberts and Nussbaum understand the connection between emotion and motivation. For now, it suffices to note that both take emotion-and so motivation - to be something that emerges from a suitably rich construal or perception of one's situation.
} 
out, consider a situation where you're contemplating taking a new job in a big city. In coming to the conclusion that the lifestyle you would have in the city counts favor of taking the job, you not only consider facts about that city and the job (e.g., the cultural richness and energy of urban life; the new, exciting networking opportunities; a more diverse set of career paths) but also contrast them with the facts about the comfortable-but decidedly quiet-life you now have. Through this rich process of understanding - construing - what living in the city would be like, and in comparing it to your current situation, you conclude that the excitement and resources of the city are a better fit with your career plans and lifestyle. A motivation to accept the job thus emerges.

While the above helps Scanlon illustrate how motivation can emerge from the cognitive process of construal, one might still worry that it doesn't do enough to explain how motivation emerges from a rich understanding of one's situation. In response, Scanlon could make a companions in guilt move. That is, he could maintain that although he hasn't provided an analysis of emergence, he has pointed us to intuitive examples of it thought the duck-rabbit, fish, and fear cases. He could then insist that whatever emergence amounts to in those familiar examples, normative judgment involves the same thing.

Turning to consideration (3), we can see that the duck-rabbit, fish, and fear cases also reveal that the cognitive process of construing is a process that beings like us can engage. As for condition (4), we now have resources to explain why the distinctive judgments of other non-natural domains (e.g., mathematics) aren't tied to motivation. As we saw in the fish example, the types of meaningful sentences that one can see in a given string of words are shaped and constrained by certain factsnamely, facts about the associated meaning and grammar rules. Similarly, whether the judgments of a given domain have rational connections to motivation is a function of certain facts-namely, facts about the distinctive concepts of those domains. More specifically, while concepts like 'normative judgment' and 'agency' presuppose a rational tie between (e.g.) believing one ought to $a$ and one's doing $a$, the central concepts of other non-natural domains do not presuppose a similar tie to action. Consider: the belief that 13 is prime may have rational connections to other beliefs (e.g., that 13 is not divisible without remainder); but it does not commit one to a particular course of action in the way that judging you have good reason to stay healthy does.

Finally, the above discussion helps us see how construals can enrich our understanding of error. Just like in the examples Roberts provides, normative judgment allows for two types of error. First, there are analogues of the failures of understanding we saw for the 'fish' string. If one does not properly understand either the relevant normative concepts (e.g., reason, agent) or the particulars of one's circumstances, one could fail to do as one judges one ought. For instance, one might see that $p$ counts in favor of doing $a$ in $c$, but because of an insufficient understanding of one's circumstances, one does not see $p$ as a decisive reason-so one isn't motivated to $a$. Alternatively, one might not do $a$ because one fails to fully appreciate what is means for a reason to be conclusive. Thus in failures of understanding, we appear to capture what Scanlon has in mind when he notes that someone who doesn't to see $p$ as a reason for doing act a 'is being irrational' (55). 
Second, there's an analogue of what I called processing failures. Here one understands one's situation and the relevant normative concepts, but one nonetheless fails to act in accordance with one's judgment about the reasons one has. Fleshing this out, recall the earlier example of failing to see the rabbit despite having the relevant concepts and understanding of the figure (e.g., the two protrusions are the ears). In such a case, the cognitive mechanisms that underlie one's capacity for visual construal have broken down-one sees the parts and understand the relations between them, but the larger whole fails to emerge. Scanlon could maintain that one experiences a similar failure of the normal functioning of one's cognitive processes when one doesn't do as one judges one ought. Suppose that although you fully understand that the facts about what your life in the city would be like provide you with conclusive reason for taking the job, you are nonetheless unmotivated to accept the offer. Here too, the 'normal processes' that underlie normative judgment-your capacity to properly construe your situationhave broken down: while you understand the fit between your lifestyle in the city and taking the job, the associated motivation to accept the position fails to emerge.

Moreover, this discussion draws out how errors of this second type manifest a more serious form of irrationality. After all, in processing failures, the problem isn't a mere failure of understanding-you understand perfectly well what you have reason to do. Yet, despite this understanding, you're left unmoved by your judgment about what you have reason to do (56). If that's right, then Scanlon not only gets a two-fold account of error, but also one that provides a richer response to the normative question.

The upshot, then, is that looking to construals provides important resources that enhance Scanlon's ability to meet the five demands for a reasons fundamentalist theory of mind.

\section{Reasons fundamentalism vindicated? Three reasons to worry}

Despite the above progress, there are three reasons to be concerned with the augmented reasons fundamentalism that we have developed on Scanlon's behalf.

Problem 1: Do we really get a rational connection to motivation? Both Nussbaum and Roberts take emotions to be intimately connected to action. But they differ in their understanding of the nature of this connection-differences that reveal trouble for the suggestion that looking to cognitivist theories of emotion can help Scanlon bolster his account of how normative judgments motivate.

First consider Nussbaum's account. As we've seen, she explains the connection between emotion and action by pointing to the rich evaluative content that's distinctive of emotion: emotions are 'acknowledgements of our goals and their status' in our lives and it's this acknowledgement of our goals/values that enables emotions to motivate us (2001: 135). For me to fear the dog-to be moved to escape-it's not enough for me to just see the dog as aggressive; I must acknowledge the dog as a threat to my well-being (41). But even with examples like this, the role that acknowledgement goals and values plays remains obscure-what explains why I couldn't remain unmoved despite acknowledging the dog as a threat 
to my well-being? As others have noted, explaining how Nussbaum's cognitivist account could explain how emotions motivate seems to require taking emotions to engage desires as well as beliefs (e.g., Marks 1982; Green 1992).

In fact, and importantly for our purposes, Roberts appears to agree. In developing his account of construals, he's sensitive to the possibility that only certain types of construal are connected to action (46-48). For instance, he notes that visually construing a cloud as a horse or linguistically construing the 'fish' string as a meaningful sentence has no (rational or causal) connection to motivation. But he thinks that the construals undergirding emotions are different-they're linked to motivation. In seeing a toddler toddle toward an edge with a significant drop off, one's construal of the child's situation as dangerous - that is, one's fear for the child-is tied to motivation (e.g., an effort to save the child). As Roberts sees it, emotions engage 'concern-based construals' - they are responses that have motivational upshot for the individual who experiences them because the individual comes to the situation with an antecedent concern or desire (46). Thus, your fear for the child motivates your efforts to save her because of your desire to protect her well-being. It's your construal of the situation as dangerous-in combination with that desire - that prompts your efforts to pull the child back from the edge. As he explains, “you will never feel fear if you don't care about the thing that you see as threatened" (46, emphasis added). But given that you do care, and so feel fear, we can make sense of why you act as you do. For instance, in the case of the child near the edge,

it is clear that my action, as emerging from my emotion, is "logical"; it makes rational sense: I desire the child's wellbeing and see his proximity to the precipice as a threat to his wellbeing. From this combination it "follows" that I will desire that the threat be avoided or that the child be protected against the threat. ... The actions that follow from this fear ... will be broadly rational in being responsive to the emotion: the situational perception with integrated concern (fear). (2013: 114)

But if Roberts is right about how construals operate, then they cannot do the work Scanlon needs them to do. After all, his comments indicate-pace Nussbaum-that there is a gap between the (merely) cognitive act of construing something in a certain way and being motivated to act as a result of that construal-a gap that we need desires or some other conative state (e.g., concern) to fill. ${ }^{6}$

\footnotetext{
${ }^{6}$ One might think that Andrea Scarantino's motivational theory of emotion (2015) offers a better model for Scanlon. After all, on Scarantino's account, emotions are states that "represent how things are (mindto-world) and how things are to be (world-to-mind) at the same time" (177); as such, his motivational theory offers an account of emotion that appears better suited to Scanlon's purposes. But there are two problems with this suggestion. First, emotions for Scarantino are, in the first place, motivational statesspecifically, action tendencies-that happen to also have representational content (156). So, initial appearances to the contrary, his model is a poor fit for Scanlon. After all, and as we've seen, Scanlon needs an account on which normative judgments are, in the first place, belief-like states that have a rational tie to motivation (e.g., 66-67). Thus, following Scarantino does not appear to help Scanlon secure conditions (1) and (2) from §2. Second, Scarantino's own discussion of emotions as states with dual directions of fit is schematic, providing little by way of an answer to (e.g.) concerns about the plausibility
} 
Problem 2: Do normative judgments makes sense of actions? Central to Scanlon's account of motivation is the claim that commonsense points to a rational connection between normative belief_or judgment—and action: someone who judges that she has reason to do $a$ tends to do $a$; and if she doesn't, she is practically irrational. Let's grant that Scanlon is correct that this claim (namely, that normative judgments have a rational tie to action) has the status of a platitude (but see, e.g., Brink 1986; Dreier 2000). Having done that, one still might worry about the apparent effectiveness of this platitude in substantiating Scanlon's further contention that normative beliefs can rationalize actions (53).

To better draw out the concern, notice that 'normative judgment' is ambiguous between (1) judgment understood as a belief-like state and (2) judgment understood as a conative state (e.g., Gibbard 2003). Recognizing this reveals trouble. After all, if we understand the platitude along the lines of (1), then we no longer have a platitudinous claim - the idea that normative beliefs have a rational tie to motivation is hardly uncontroversial. But if we instead understand the platitude along the lines of (2), then-though we have a platitude (roughly: motivational states are tied to motivation) - we don't have a claim that is of any use to a cognitivist like Scanlon.

Scanlon might try to resist this dilemma by contesting the move to analyze 'normative judgment': rather than unpacking it as (1) or (2), we should just consider it at the level of 'commonsense' (whatever that might amount to). If we do this, we retain both the platitudinous status of the platitude and the plausibility of the claim that beliefs rationalize just as well as desires. ${ }^{7}$ But this move comes at a big cost. As we've seen (\$2), in rejecting the direction of fit model of the belief/desire distinction, Scanlon takes on the burden of providing an alternative account-a reasons fundamentalist-friendly theory of mind. But recognizing the ambiguity in 'normative judgment' draws out that if the alternative theory of mind rests just on platitudes, it cannot do the needed work: meeting the explanatory demand issued in $\$ 2$ requires providing a more substantive account of 'normative judgment' than what we get from commonsense platitudes alone. So to deny that the platitude is problematically ambiguous, and so deny that an analysis of 'normative judgment' is needed, is to give up on the project of providing a substantive reasons fundamentalist theory of mind-it amounts to an acknowledgment that the explanatory demand issued in $\$ 2$ cannot be met.

Problem 3: A robust account of error and irrationality? As we have seen, our augmented reasons fundamentalism allows for two forms of error: failures of understanding and processing failures. While this is progress, neither option turns out to be rich enough to capture the failures that are constitutive of irrationalitythat is, failures that are distinct from, and more normatively significant than, mere ignorance, inattentiveness, confusion, and the like. Thus, the reasons fundamentalist answer to the normative question remains unsatisfactory.

Footnote 6 continued

of such states. Thus, it's unclear that the Scarantino proposal would provide Scanlon with the additional explanatory resources he needs.

7 Something like this is suggested by Scanlon's comments on p. 61. It also seems of a piece with his quietist account of reasons as both resisting analysis and metaphysically light-weight. 
First consider failures of understanding. As failures that result from not fully understanding normative concepts like 'reason' and 'agent' or not properly appreciating one's circumstances, these failures seem nothing more than the sort of run of the mill failings that result from ignorance, inattention, confusion, and other deficits of uptake. So we don't get the richer form of error we were looking for. In this way, what we've labeled 'processing failures' represent an advance: errors that result from the failure of normal cognitive functioning are distinct from errors resulting from a failure of understanding-one has the relevant conceptual and situational knowledge, yet one's underlying cognitive processes nonetheless break down.

But to understand the irrationality at issue in the normative question as a kind of short circuiting, as the processing failure proposal does, is to suggest that an agent who fails to act on the reasons she takes herself to have is no different than a gumball machine that every 100 or so uses fails to deliver a gumball. After all, in both cases there's a failure in the 'normal processes' that lead from inputs to outputs (Scanlon 2014: 56). While there's certainly a problem here, it seems different in kind from the type of problem that we're interested in when we make attributions of irrationality: to say that someone is irrational is to say that they are defective in some deeper-not merely functional-sense. How, exactly, one explains this deeper deficiency is an open question. One might understand it, for instance, as a kind of incoherence-one's thinking and one's actions fail to form the right kind of coherent whole (e.g., Williams 1979; Dreier 2014b: 164). Alternatively, one might understand the irrationality as a type of inconsistency or self-contradiction: one doesn't act in accordance with the plans or practical identities one has committed oneself to (e.g., Gibbard 2003; Korsgaard 1996; c.f., Dreier 2014a: 179-180). Though different in the details, what these accounts share is the thought that the irrationality of not doing what you judge yourself to have most reason to do involves more than just a functional breakdown-it's a distinctive and particularly troubling kind of failure. If that's right, then Scanlon's proposal fails to adequately capture the form of irrationality that's at the heart of worries about quietism's ability to answer the normative question. ${ }^{8}$

\section{Conclusion}

Here's where things stand. We've made a significant effort to develop a theory of mind that could improve Scanlon's ability to answer the normative question. Central to this project was our development of an analogy between cognitive theories of emotion and Scanlon's account of normative judgment—both proposals, after all, are accounts of cognitive states that have robust ties to motivation. But the observations of $\S 4$ suggest that there's good reason to be worried about the plausibility of this

\footnotetext{
${ }^{8}$ One might think that Scanlon could respond by augmenting his account of PRAs so that the decision making of PRAs is subject to demands for coherence and consistency of the sort noted in the text. But such a suggestion fits poorly with Scanlon's concerns about wedding his reasons fundamentalism to a substantive account of rationality of this sort (e.g., 7-10).
} 
alternative theory of mind. Though emotions (as concern-based construals) have connections to motivation, the nature of the connection that emotions exhibit is a poor fit for what Scanlon needs. We also saw that there's good reason to doubt whether a Scanlonian account can give a sufficient account of what's wrong about not doing what you judge yourself to have most reason to do. While the discussion here doesn't rule out the possibility of an alternative route to a reasons fundamentalist theory of mind, it should make us skeptical. After all, cognitivist accounts of emotions seemed particularly well-placed to meet the explanatory demands that Scanlon's proposal faces. So seeing that it falls short of what's needed should raise worries about whether there's an alternative that could do better.

Acknowledgements Thanks to Anne Margaret Baxley, Eric Brown, Billy Dunaway, and Eric Wiland for input on an earlier version of this paper.

\section{References}

Brink, D. (1986). Externalist moral realism. The Southern Journal of Philosophy, 24(supplement), $23-41$. Coleman, M. (2008). Directions of fit and the Humean theory of motivation. Australasian Journal of Philosophy, 86, 127-139.

Deonna, J., \& Teroni, F. (2012). The emotions: A philosophical introduction. Abingdon: Routledge.

Dreier, J. (2000). Dispositions and fetishes. Philosophy and Phenomenological Research 619-638.

Dreier, J. (2014a). Can reasons fundamentalism answer the normative question? In G. Bjornsson, C. Strandberg, R. Olinder, J. Eriksson, \& F. Bjorklund (Eds.), Motivational internalism. Oxford: Oxford University Press.

Dreier, J. (2014b). Another world. In M. Smith \& R. Johnson (Eds.), Passions and projections (pp. 155-170). New York: Oxford University Press.

Dworkin, R. (1996). Objectivity and truth: You'd better believe it. Philosophy \& Public Affairs, 25, 87-139.

Enoch, D. (2011). Taking morality seriously. Oxford: Oxford University Press.

Gibbard, A. (1990). Wise choices, apt feelings. Cambridge, MA: Harvard University Press.

Gibbard, A. (2003). Thinking how to live. Cambridge, MA: Harvard University Press.

Green, O. (1992). The emotions: A philosophical theory. Dordrecht: Kluwer.

Korsgaard, C. (1996). Sources of normativity. Cambridge: Cambridge University Press.

Korsgaard, C. (2008). Realism and constructivism in twentieth century moral philosophy. In C. M. Korsgaard (Ed.), The Constitution of agency: Essays on practical reason and moral psychology. Oxford: Oxford University Press.

Marks, J. (1982). A theory of emotion. Philosophical Studies, 42, 227-242.

McPherson, T. (2010). Against quietist normative realism. Philosophical Studies, 154, 223-240.

Nussbaum, M. (2001). Upheavals of thought. Cambridge: Cambridge University Press.

Parfit, D. (2011). On what matters. Oxford: Oxford University Press.

Roberts, R. (2013). Emotions in the moral life. Cambridge: Cambridge University Press.

Scanlon, T. M. (1998). What we owe to each other. Cambridge, MA: Harvard University Press.

Scanlon, T. M. (2014). Being realistic about reasons. Oxford: Oxford University Press.

Scarantino, A. (2015). The motivational theory of emotion. In J. D'Arms \& D. Jacobson (Eds.), Moral psychology and human agency (pp. 156-185). Oxford: Oxford University Press.

Shafer-Landau, R. (2003). Moral realism: A defense. Oxford: Clarendon.

Smith, M. (1994). The moral problem. Oxford: Blackwell.

Tanenbaum, S. (2006). Direction of fit and motivational cognitivism. In R. Shafer-Landau (Ed.), Oxford studies in metaethics (Vol. 1, pp. 235-264). Oxford: Oxford University Press.

Williams, B. (1979). Internal and external reasons. In Moral luck. Cambridge: Cambridge University Press.

Wodak, D. (2017). Why realists must reject normative quietism. Philosophical Studies, 174, 2795-2817.

Zangwill, N. (1998). Directions of fit and normative functionalism. Philosophical Studies, 91, 173-203. 